\title{
Combination of gene expression patterns in whole blood discriminate between tuberculosis infection states
}

\author{
Adane Mihret ${ }^{1,2^{*}+}$, Andre G Loxton ${ }^{3 \dagger}$, Yonas Bekele ${ }^{1}$, Stefan HE Kaufmann ${ }^{4}$, Martin Kidd ${ }^{5}$, Mariëlle C Haks ${ }^{6}$, \\ Tom HM Ottenhoff ${ }^{6}$, Abraham Aseffa ${ }^{1}$, Rawleigh Howe ${ }^{1}$ and Gerhard Walzl ${ }^{3}$
}

\begin{abstract}
Background: Genetic factors are involved in susceptibility or protection to tuberculosis (TB). Apart from gene polymorphisms and mutations, changes in levels of gene expression, induced by non-genetic factors, may also determine whether individuals progress to active TB.

Methods: We analysed the expression level of 45 genes in a total of 47 individuals ( 23 healthy household contacts and 24 new smear-positive pulmonary TB patients) in Addis Ababa using a dual colour multiplex ligationdependent probe amplification (dcRT-MLPA) technique to assess gene expression profiles that may be used to distinguish TB cases and their contacts and also latently infected (LTBI) and uninfected household contacts.

Results: The gene expression level of BLR1, BCI2, IL4d2, ILTR, FCGR1A, MARCO, MMP9, CCL19, and LTF had significant discriminatory power between sputum smear-positive TB cases and household contacts, with AUCs of 0.84, 0.81 , $0.79,0.79,0.78,0.76,0.75,0.75$ and 0.68 respectively. The combination of $B C 12, B L R 1, F C G R 1 A, I L 4 d 2$ and MARCO identified $91.66 \%$ of active TB cases and $95.65 \%$ of household contacts without active TB. The expression of CCL19, TGFB1, and Foxp3 showed significant difference between LTBI and uninfected contacts, with AUCs of 0.85, 0.82, and 0.75, respectively, whereas the combination of BPI, CCL19, FOXP3, FPR1 and TGFB1 identified $90.9 \%$ of QFT and 91.6\% of $\mathrm{QFT}^{+}$household contacts.
\end{abstract}

Conclusions: Expression of single and especially combinations of host genes can accurately differentiate between active TB cases and healthy individuals as well as between LTBI and uninfected contacts.

\section{Background}

An effective immune response controls Mycobacterium tuberculosis (MTB) in the majority of infected individuals, and only $3-10 \%$ of those infected persons develop clinical disease and symptoms within the first two years after infection (primary tuberculosis, TB) while another $5 \%$ develop the disease later in life (reactivation TB) [1]. Defining the differences in the immune responses between those who control versus those who fail to control the infection is an important prerequisite for the development

\footnotetext{
* Correspondence: adane_mihret@yahoo.com

${ }^{\dagger}$ Equal contributors

'Armauer Hansen Research Institute, Addis Ababa, Ethiopia

${ }^{2}$ Department of Microbiology, Immunology and Parasitology, School of Medicine, College of Health Sciences, Addis Ababa University, Addis Ababa, Ethiopia

Full list of author information is available at the end of the article
}

of interventions that will improve immune-mediated protection. Various studies have confirmed that genetic factors are involved in the disease and could be key for the different outcomes of MTB infection [2,3]. A recent study showed a significant difference in the type and magnitude of immune responses between UK and Malawi children against BCG. Th1 related cytokines were present at higher levels in the UK infants whereas abundances of innate proinflammatory cytokines, regulatory cytokines, interleukin 17, Th2 cytokines, chemokines and growth factors were elevated in the Malawi infants, possibly due to genetic but also environmental factors [4].

Apart from genetic factors lead to differences among individuals [3,5-10], environment-induced changes in gene expression occur during the dynamic interaction between the immune system and M. tuberculosis [11-14]. Therefore, assessing differential regulation of gene expression 
may help identifying biomarkers to distinguish the different MTB exposure outcomes. Recent studies have indicated that Fc gamma receptor $1 B$ (FCGR1B) [14], combined with expression patterns of FCGR1A (CD64), $R A B 33 A$ and $L T F$ (lactoferrin) [12] and CD3E, CD8A, IL7R, BLR1, CD19, FCGR1A, CXCL10, CD4, TNF, BCL2, MMP9, Foxp3, CASP8, CCL4, TNRFSF1A, CASP8, Bcl2 and TNF [15] showed clear discriminatory power between TB and latent TB infection (LTBI). Expression of RIN3, LY6G6D, TEX264, and C14orf2 genes identified active, cured, recurrent or LTBI [11]. Therefore, we analysed 45 genes targeting immune cell subset markers, $\mathrm{T}$ regulatory cell markers, effector $\mathrm{T}$ cell markers, apoptosis related genes and four housekeeping genes using a dual color multiplex ligation-dependent probe amplification technique (dcRT-MLPA) to assess gene expression profiles to distinguish between the different clinical groups. These markers were selected for gene expression profiling, as described in Joosten et al. [15].

\section{Methods}

A total of 47 subjects (23 healthy household contacts and 24 microbiologically confirmed new smear-positive HIV negative pulmonary TB patients) attending Arada, T/Haimanot, Kirkos and W-23 health centres in Addis Ababa were recruited upon informed consent.

The diagnosis of active TB in the health centres was based on the national guidelines of at least two positive sputum smears for acid-fast bacilli (AFB) in three specimens collected from each patient as spot-morning-spot samples. All sputum samples from TB cases were cultured for mycobacteria and confirmed as MTB. We obtained ethical clearance from AHRI/ALERT Ethics Review Committee (P015/10) and National Research Ethics Review Committee (NRERC) (3.10/17/10).

QuantiFERON-TB Gold In Tube (QFT-GIT) test was used to detect LTBI as per the manufacturer's instructions (Cellestis Limited, Carnegie, Victoria, Australia) [16]. Three $\mathrm{ml}$ venous blood was directly collected into three 1-ml QFT-GIT tubes (Cellestis, Australia); one negative control (Nil) tube containing only heparin, another tube containing phytohaemagglutinin (PHA) as positive control (Mitogen) and the third tube containing overlapping peptides representing the entire sequences of ESAT-6, CFP-10 and TB7.7 (TB Antigen). The tubes were shaken vigorously and then incubated at $37^{\circ} \mathrm{C}$ for about 20 hrs. They were then centrifuged and plasma was harvested and frozen at $-20^{\circ} \mathrm{C}$ until ELISA was performed. The level of IFN- $\gamma$ was measured using the QFT ELISA kit (Cellestis, Australia). The ELISA readout and data interpretation were carried out using the QFT software (Version 2.50, Cellestis, Australia). As recommended by the manufacturer, a positive test for MTB infection was considered if the IFN- $\gamma$ difference was $\geq 0.35 \mathrm{IU} / \mathrm{ml}$ (TB antigens-Negative control). The result of the test was considered indeterminate when an antigen-stimulated sample was $\leq 0.35 \mathrm{IU} / \mathrm{ml}$ (TB antigens-Negative control) if the value of the positive control was less than $0.5 \mathrm{IU} / \mathrm{ml}$ (Positive control-Negative control).

\section{Blood collection and RNA extraction}

Venous blood was collected into PAXgene Blood RNA tubes and RNA extraction performed following the manufacturer's instructions (PAXgene Blood RNA Kit, PreAnalytiX, QIAGEN) [17]. Briefly, blood containing tubes were centrifuged at $3000 \mathrm{rpm}$ for $10 \mathrm{~min}$, supernatant discarded, pellet lysed and washed, followed by treatment with proteinase $\mathrm{K}$ and ethanol precipitation. To remove contaminating DNA, RNase-free DNase was added (QIAGEN, Germany), washed and finally the RNA was eluted with RNase-free water, concentration-quantified using a GeneQuant spectrophotometer (Amersham Biosciences, UK) and stored at $-80^{\circ} \mathrm{C}$ until use.

\section{Dual colour multiplex ligation-dependent probe amplification (dcRT-MLPA)}

dcRT-MLPA was done according to ref Joosten et al. [15]. First, cDNA was synthesised from RNA by using a RT primer mix and then denatured and incubated overnight with the mixture of customized probes to allow the probes to hybridize with the target genes. The two separate probes were then fused together using a ligase enzyme. The ligated probes hybridized with the target genes, were amplified. Finally the PCR product was separated by electrophoresis and the RNA expression levels were quantified by measuring the fluorescence intensity.

A set of probes was designed by Leiden University Medical Centre (LUMC), Leiden, The Netherlands, and comprised sequences for 45 genes targeting immune cell subset markers, $\mathrm{T}$ reg markers, effector $\mathrm{T}$ cell markers and apoptosis related genes and four housekeeping genes. Genes associated with active TB disease or protection against disease, as described in the literature, were included in the study. The list of genes for which a set of probes was designed is shown in Table 1.

After completion of the dcRT-MLPA reaction, amplified products were analysed with an ABI-310 capillary sequencer in GeneScan mode (Applied Biosystems). The data from the sequencer were analysed using the GeneMapper software. Further analysis was done using Microsoft Excel spread sheet software. Finally data were normalised by selecting one of the housekeeping genes, which was most stably expressed across the evaluated samples (ABR, GUSB, GAPDH or B2M). The coefficient of variation was calculated to determine which reference gene was most stably expressed across the evaluated samples. GAPDH was selected and all samples were 
Table 1 List of target genes for dual colour multiplex ligation-dependent probe amplification (dcRT-MLPA)

\begin{tabular}{llll}
\hline BCl2 & CD8a & IL4 & RAB33 \\
BLR1 & CD14 & IL4d2 & SEC14L1 \\
BPI & CD19 & IL7R & SPP1 \\
CASP8 & CD163 & IL10 & TGFB1 \\
CCL4 & CTLA4 & IL22RA1 & TGFBR2 \\
CCL13 & CXCL10 & LAG3 & TNF \\
CCL19 & FASLG & LTF & TNFRSF1A \\
CCL22 & FCGR1A & MARCO & TNFRSF1B \\
CCR7 & FOXP3 & MMP9 & TIMP2 \\
CD3E & FPR1 & NCAM1 & TNFRSF18 \\
CD4 & IFN $Y$ & RAB13 & Reference genes \\
& IL2Ra & RAB24 & ABR, B2M, GAPDH, GUSB \\
\hline
\end{tabular}

normalized over GAPDH. A peak area of 200 for signals was assigned as threshold value for noise cut off in GeneMapper. The relative peak size of the product from the probe recognition sequence was compared with the relative peak size of the product from a control.

\section{Statistical analysis}

The data were analyzed using Graph Pad Prism software, version 4.0 (La Jolla, CA 92037 USA) and STATISTICA software, version 10, Statsoft (Ohio, USA). Nonparametric Mann-Whitney $U$ tests were performed to find the significance of the observed differences. Best subsets discriminant analysis (GDA) and receiver operator characteristic (ROC) curve analysis were used to evaluate the predictive abilities of combinations of biomarkers and to generate cut off values for differentiating between MTB infection states (described in [18]). A p value less than 0.05 was considered as statistically significant.

\section{Results}

We enrolled 24 subjects with culture confirmed $\mathrm{HIV}^{-}$ active tuberculosis $\mathrm{TB}$ and $23 \mathrm{HIV}^{-}$household contacts

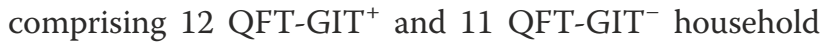
contacts. The mean age of TB patients was $31.6 \pm 1.4$ and $46.5 \%$ of the participants were females. The mean age for household contacts was $28.3 \pm 2.3$ and $47.6 \%$ of household contacts were females.

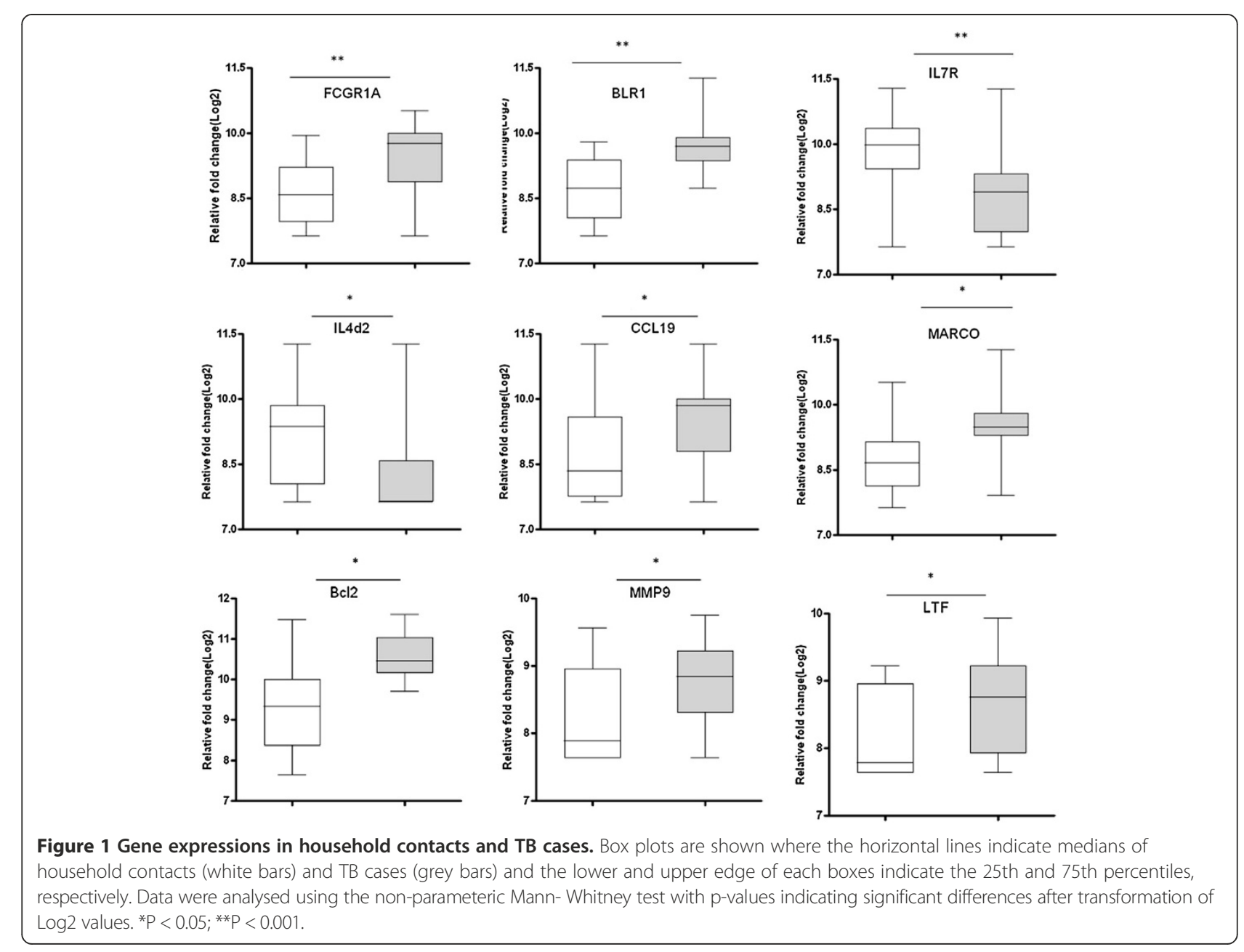


Gene expression of TB patients and household contacts RNA samples from the $24 \mathrm{~TB}$ patients and 23 healthy household contacts were analysed with dcRT-MLPA and significant gene expression differences were observed between these two groups. The gene expression levels of BLR-1, MARCO, CCL-19, MMP-9, LTF, Bcl-2, and $F C \gamma R 1 A$ were statistically higher in TB patients than contacts $(\mathrm{p}<0.05)$, whereas the expression levels of IL4 $\delta 2$ and $I L 7 R$ were statistically higher in healthy contacts than TB cases $(\mathrm{p}<0.05)$ (Figure 1$)$.

These most accurate single gene markers that differentiated TB cases and contacts were BLR1, Bcl2, IL4d2, IL7R, FcgR1A, MARCO, MMP9, CCL19, and LTF with area under the curves (AUCs) of 0.84, 0.81, 0.79, 0.79, $0.78,0.76,0.75,0.75$ and 0.68 , respectively (Figure 2). We did a best subsets discriminant analysis, revealing that a combination of five genes gave a better discriminatory power: the combination of $B c l 2, B L R 1, M A R C O$, FC $Y R 1 A$ and IL4S2 detected $95.65 \%$ (determined using leave-one-out cross validation) of household contacts and $91.66 \%$ of TB cases were correctly classified (Table 2).
FcyR1A and IL4 $\delta 2$ were the most frequently occurring markers in the GDA biomarker combinations differentiating between the TB cases and household contacts (Figure 3).

\section{Gene expression of LTBI household contacts}

We further classified the household contacts into LTBI and uninfected groups using the QFT test to assess the effect of LTBI on the expression level of different genes. The expression levels of Foxp3, CCL19 and TGF $\beta$ were significantly higher $(\mathrm{p}<0.05)$ in $\mathrm{QFT}^{+}$than $\mathrm{QFT}^{-}$contacts (Figure 4).

The most accurate single gene markers that differentiated $\mathrm{QFT}^{+}$and $\mathrm{QFT}^{-}$contacts were CCL19, TGFB1, and Foxp3 with AUCs of $0.85,0.82$, and 0.75 respectively (Figure 5). A best subsets discriminant analysis (GDA) of the data indicated that optimal discrimination of LTBI and uninfected household contacts could be achieved with combinations of five variables, BPI, CCL19, Foxp3, FPR1 and TGFB1. A combination of these genes detected $90.9 \% \mathrm{QFT}^{-}$household contacts using leave-one-

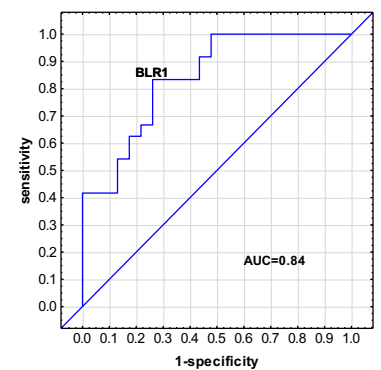

1-specificity
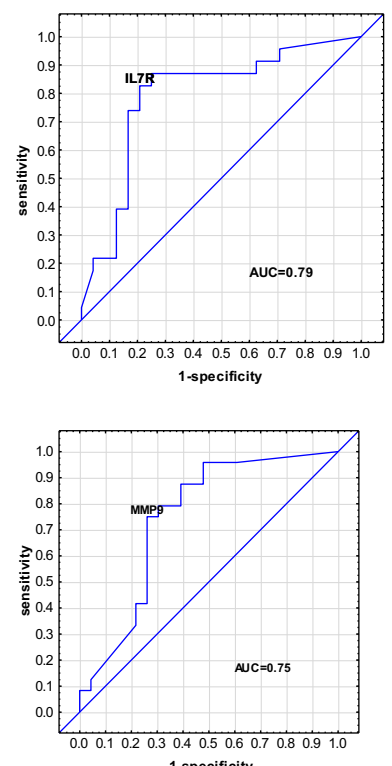

1-specificity

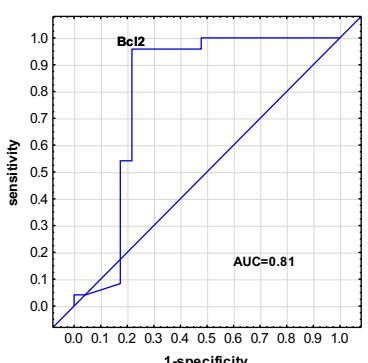

1-specificity
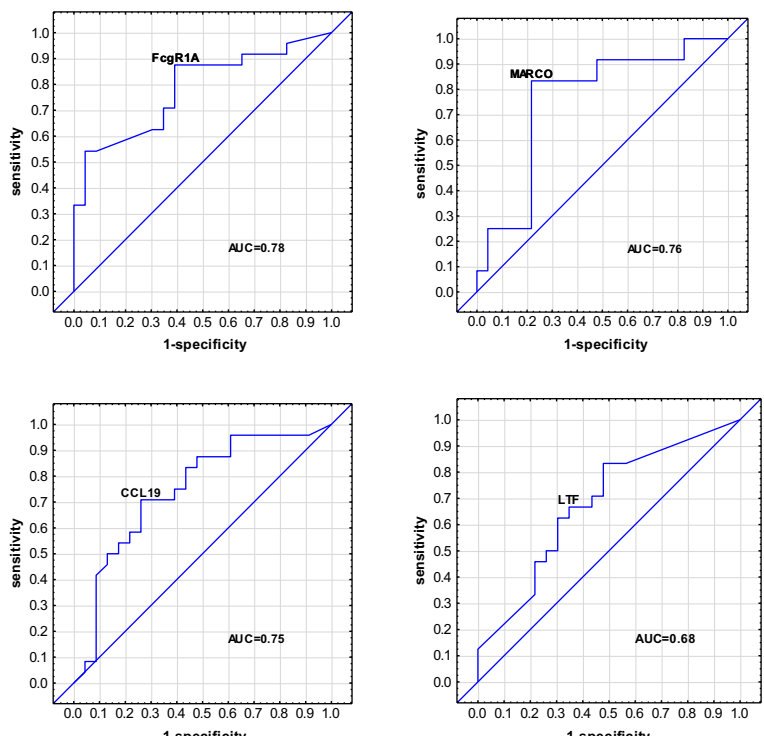

1-specificity

Figure 2 Receiver operator characteristics curves showing the accuracies of individual genes in discriminating between active TB cases and household contacts. Receiver operator characteristic (ROC) curves for the accuracies of single analytes to ifferentiate between active TB and household contacts. AUC = Area under the curve. 
Table 2 General discriminate analysis of five marker combinations to discriminate active TB and household contacts

\begin{tabular}{|c|c|c|c|c|c|c|c|}
\hline \multirow[b]{3}{*}{ Genes } & \multicolumn{2}{|c|}{ Household contacts } & \multicolumn{2}{|c|}{ TB cases } & \multirow{3}{*}{ Wilks lambda } & \multirow[b]{3}{*}{$f$} & \multirow[b]{3}{*}{$p$ value } \\
\hline & $\begin{array}{c}\text { Resubstitution } \\
\text { classification }\end{array}$ & $\begin{array}{l}\text { Leave-one-out } \\
\text { cross }\end{array}$ & $\begin{array}{l}\text { Resubstitution } \\
\text { classification }\end{array}$ & $\begin{array}{l}\text { Leave-one-out } \\
\text { cross }\end{array}$ & & & \\
\hline & Matrix & Validation & Matrix & Validation & & & \\
\hline 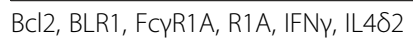 & 95.65 & 91.3 & 95.83 & 95.83 & 0.74 & 14 & $<0.001$ \\
\hline 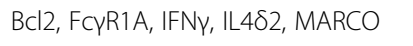 & 91.3 & 91.3 & 95.83 & 91.66 & 0.72 & 15.8 & $<0.001$ \\
\hline Bcl2, BLR1,CD163, FcyR1A, IL482 & 95.65 & 95.65 & 91.66 & 87.5 & 0.75 & 13.65 & $<0.001$ \\
\hline Bcl2, BLR1, FcyR1A, IL482, MARCO & 95.65 & 95.65 & 95.83 & 91.66 & 0.73 & 14.95 & $<0.001$ \\
\hline Bcl2, CD19, FcyR1A, IL482, MARCO & 95.65 & 95.65 & 91.66 & 91.66 & 0.75 & 13.21 & $<0.001$ \\
\hline $\mathrm{BCl} 2, \mathrm{BLR} 1, \mathrm{CD} 19, \mathrm{~F} C \mathrm{R} 1 \mathrm{~A}, \mathrm{IL} 4 \delta 2$ & 91.3 & 91.3 & 95.83 & 87.5 & 0.77 & 11.98 & 0.0013 \\
\hline $\mathrm{Bc} \mid 2, \mathrm{BPI}, \mathrm{Fc} \gamma \mathrm{R} 1 \mathrm{~A}, \mathrm{IL} 4 \delta 2, \mathrm{MARCO}$ & 95.65 & 95.65 & 91.66 & 95.83 & 0.72 & 16.11 & $<0.001$ \\
\hline BLR 1, FcyR1A, IFNy, IL482, MMp9 & 95.65 & 86.95 & 95.83 & 91.66 & 0.75 & 13.46 & $<0.001$ \\
\hline BLR 1, FcyR1A, IFNY, IL4d2, RAB13 & 91.3 & 86.95 & 95.83 & 91.66 & 0.76 & 13.13 & $<0.001$ \\
\hline BLR2, FcyR1A, IL482, MARCO, SPP1 & 95.65 & 95.65 & 95.83 & 87.5 & 0.71 & 16.7 & $<0.001$ \\
\hline
\end{tabular}

Percentage indicates the proportion of groups discriminated using the combination of markers; and $f$ is the measure of fit.

out cross validation, and detected $91.6 \%$ of $\mathrm{QFT}^{+}$ (Table 3). FoxP3 and CCL19 were the most frequently occurring markers in the GDA biomarker combinations differentiating between LTBI and uninfected household contacts (Figure 6).

\section{Discussion}

Quantitative changes in gene expression could potentially be used as biomarkers to classify the different clinical outcomes of MTB exposure, with potential future applications in the evaluation of new drugs and vaccines. A recent study by Kaforou M. et al. [19] reported that blood transcriptional signatures distinguished TB from other conditions prevalent in HIV-infected and -uninfected African adults. We tested expression of 45 genes aimed at characterizing unique gene expression profiles in view of the complexity of the infection process and outcomes of

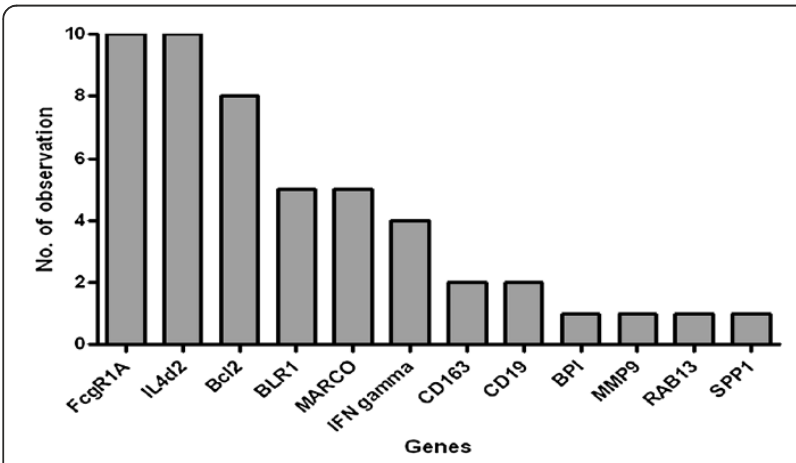

Figure 3 Frequency of individual genes in top 10 models for discriminating between active TB cases and household contacts. The columns represent the number of inclusions of individual markers into the most accurate five-analyte models by general discriminant for discriminating between active pulmonary TB cases and contacts.
MTB exposure and infection. This approach emphasizes the discriminatory abilities of single biomarkers, but more importantly combinations of biomarkers. In this study we used a dcRT-MLPA technique to simultaneously identify multiple genes that are differentially expressed in TB cases and their contacts and identify nine genes that were differentially expressed between TB cases and their contacts. The dcRT-MLPA technology fulfils a biomarker discovery niche between unbiased approaches such as whole transcriptome analysis and targeted analysis by qRT-PCR and enables cost-effective biomarker discovery in large fieldstudies with widely available laboratory equipment.

The expression levels of FcyR1A, LTF, BLR1, MARCO, CCL-19, MMP-9, CCL4, and Bcl2 in whole blood was significantly higher elevated in TB patients than among contacts, whereas the expression of $I L 4 \delta 2$ and $I L-7 R$ were significantly higher in healthy contacts as compared to TB cases. The higher expression of $F c \gamma R 1 A$ and LTF in TB patients has been reported previously in Germany [12] with microarray analysis of PBMCs from TB patients and healthy donors and in Gambia and Paraguay with MLPA [15] and a recent study showed expression of significantly higher level expression of Fc $\gamma 1 A$ in participants with active TB than in those with LTBI before treatment regardless of HIV status or genetic background [20]. Fc $\gamma 1 A$ and LTF are essential components of antimicrobial defenses and blocking of induction of $F c \gamma R 1 A$ is one major target for the survival strategy of MTB [21]. LTF, in addition to regulating iron uptake and utilization, modulates both the innate and adaptive immune response and the potential of LTF as an adjuvant for BCG vaccination has been considered [22]. Another study in a murine model also showed that susceptibility to TB could be reduced by avoiding overload of iron using LTF [23]. 

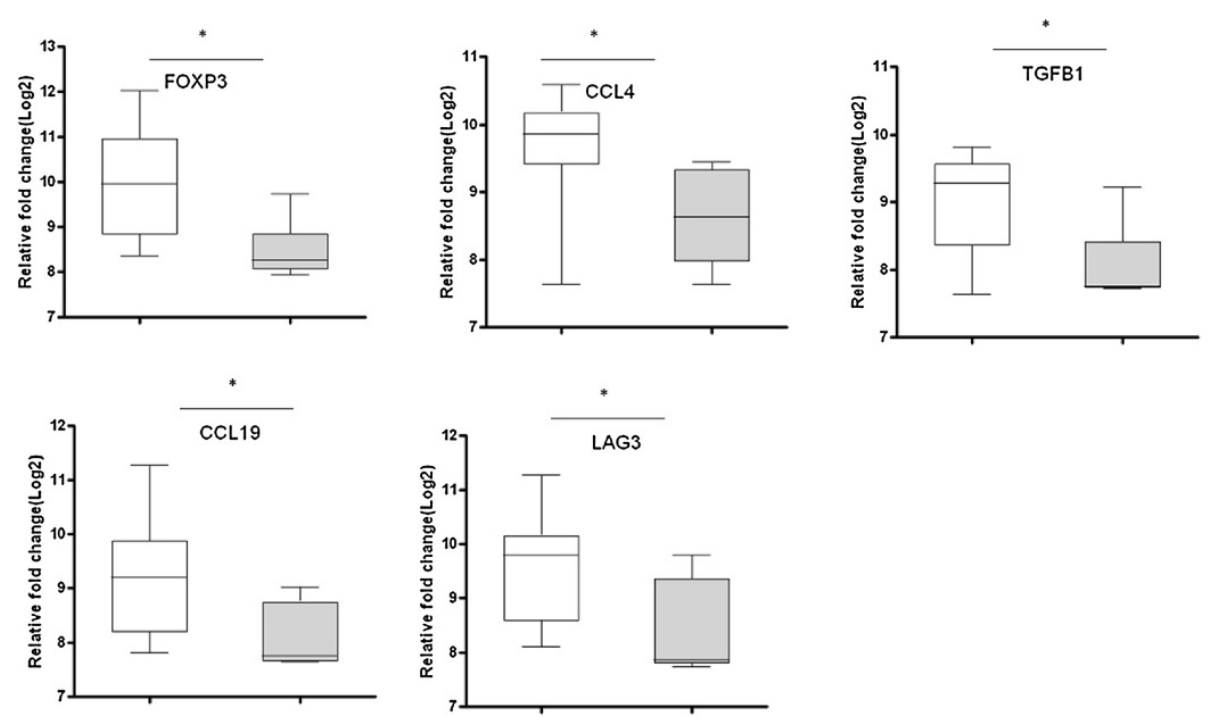

Figure 4 Gene expression in Quantiferon ${ }^{+}$and Quantiferon ${ }^{-}$household contacts. Box plots are shown with the horizontal lines indicating median levels of Quantiferon ${ }^{+}$(white bars) and Quantiferon ${ }^{-}$(grey bars) household contacts. The lower and upper edge of each box indicates the 25th and 75th percentiles, respectively. Data were analysed using nonparametric Mann-Whitney test with p-values indicating significant differences after transformation of data to Log2 values. ${ }^{*} \mathrm{P}<0.05$.

BLR1 (CXCR5) encodes a chemokine receptor and the higher expression of this gene in TB patients might help in sustaining the expression of its ligand CXCL13, which in turn attracts B cells. A role of B cells in immunity against TB has been observed in some studies [24,25]. The higher level of CCL19 in TB patients could be due to active infection where a number of crucial cells including macrophages and $\mathrm{T}$ cells are recruited to contain infection. Different in vivo and in vitro studies indicate that MTB infection of human monocyte derived macrophages, alveolar macrophages, and $\mathrm{CD} 4{ }^{+} \mathrm{T}$ cells induce upregulation of chemokine receptors and their ligands [26-28].

The higher level of MMP9 and MARCO in TB infections is in line with other previous reports, revealing higher level of MMP-9 in TB cases where it facilitates early dissemination of MTB with subsequent recruitment of macrophages, induction of Th1 type immunity and granuloma formation [29,30]. MARCO is a phagocytic receptor and MTB uses different receptors for entry into macrophages. Previous work in mouse models also showed upregulation of MARCO genes after BCG infection [31] and a low proinflammatory response of $\mathrm{MARCO}^{-1-}$ mice in response to infection with virulent MTB [32].

The remaining other genes that had discriminatory power were $B c l-2$ and $I L-4 \delta 2 . B c l-2$ is an anti-apoptotic gene and in this study, its expression was higher in TB patients. Apoptosis and autophagy likely participate in elimination of infected cells without releasing viable bacteria. Previous studies in Ethiopia and Gambia [15,33] indicate up regulation of apoptotic genes in TB patients but we did not observe these findings in our study. However, the higher expression of $\mathrm{Bcl} 2$ which we observe shown here instead could be part of a pathogen



1-specificity

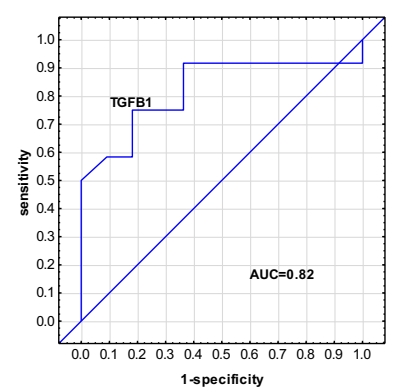

1-specificity

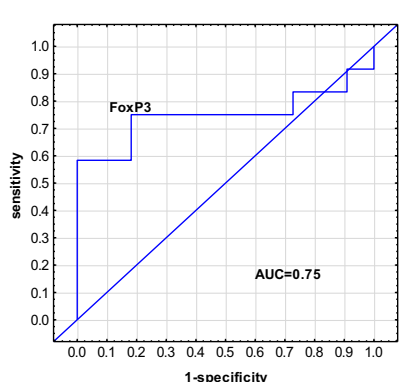

1-specificity

Figure 5 Receiver operator characteristics curves showing the accuracies of individual genes in discriminating between LTBI and uninfected household contacts. Receiver operator characteristic (ROC) curves for the accuracies of single analytes to differentiate between LTBI and uninfected household contacts. AUC = Area under the curve. 


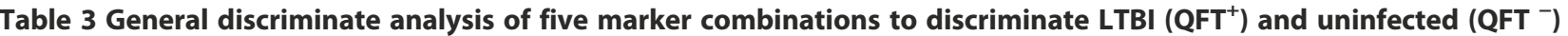
household contacts

\begin{tabular}{|c|c|c|c|c|c|c|c|}
\hline \multirow[b]{3}{*}{ Genes } & \multicolumn{2}{|c|}{ QFT negative } & \multicolumn{2}{|c|}{ QFT positive } & \multirow{3}{*}{ Wilks lambda } & \multirow[b]{3}{*}{ f } & \multirow[b]{3}{*}{$p$ value } \\
\hline & $\begin{array}{l}\text { Resubstitution } \\
\text { classification }\end{array}$ & $\begin{array}{l}\text { Leave-one-out } \\
\text { cross }\end{array}$ & $\begin{array}{l}\text { Resubstitution } \\
\text { classification }\end{array}$ & $\begin{array}{l}\text { Leave-one-out } \\
\text { cross }\end{array}$ & & & \\
\hline & Matrix & Validation & Matrix & Validation & & & \\
\hline BPI, CASP8, CCL19 and TGF $\beta 1$ & 90.9 & 81.8 & 91.6 & 91.6 & 0.84 & 17.45 & 0.093 \\
\hline BPI, CCL19, FOXP3, TGF $\beta 1$ and TIMP2 & 90.9 & 81.8 & 83.3 & 83.3 & 0.74 & 17.67 & 0.027 \\
\hline CASP8, CCL13, FOXP3 and TGF $\beta 1$ & 81.8 & 81.8 & 91.6 & 91.6 & 0.86 & 2.74 & 0.116 \\
\hline CCL19, CD14, FOXP3, IL2RA and TIMP2 & 90.9 & 90.9 & 83.3 & 83.3 & 0.62 & 10.22 & 0.005 \\
\hline CASP8, CCL19, FOXP3, RAB24 and TIMP2 & 81.8 & 81.8 & 91.6 & 91.6 & 0.92 & 1.54 & 0.23 \\
\hline CASP8, CCL19, CD163, FOXP3 and TGF $\beta 1$ & 90.9 & 81.8 & 91.6 & 91.6 & 0.92 & 1.53 & 0.23 \\
\hline CCL19, CD4, FOXP3, IL2RA and TIMP2 & 90.9 & 90.9 & 83.3 & 83.3 & 0.63 & 9.76 & 0.006 \\
\hline BPI, CCL19, FOXP3, FPR1 and TGF $\beta 1$ & 90.9 & 90.9 & 91.6 & 91.6 & 0.6 & 11.08 & 0.004 \\
\hline CASP8, CCl19, FASL, FOXP3 and TGF $\beta 1$ & 90.9 & 90.9 & 83.3 & 83.3 & 0.96 & 0.55 & 0.46 \\
\hline BPI, CCL19, FOXP3, SEC14L1 and TGF $\beta 1$ & 81.8 & 81.8 & 91.6 & 83.3 & 0.74 & 5.85 & 0.03 \\
\hline
\end{tabular}

Percentage indicates the proportion of groups discriminated using the combination of markers; and $f$ is the measure of fit.

survival strategy. Previous studies also showed that MTB or its products can inhibit apoptosis [34]. We found the expression of $I L 4 \delta 2$ to be higher in contacts than in TB patients. $I L 4 \delta 2$ is a recently described splice variant of IL4 which inhibits IL4 activity. LTBI individuals expressed high levels of Th1 cytokines and the IL4 antagonist IL4 $\delta 2$, and individuals with a high IL4 $\delta 2 /$ IL4 ratio were reported being capable of controlling MTB infection [35].

The expression of CCL19, TGF $\beta 1$, and Foxp3 discriminates LTBI and uninfected contacts with higher expression of all genes in IGRA positive latently MTB infected individuals. Their higher expression might be due to recent MTB infection, resulting in immune activation and recruitment of immune cells. CCL19 is critical for recruitment of activated immune cells. Increased expression of regulatory molecules could help regulating exacerbated immune activation and preventing excessive inflammation and resulting causing immunopathology. Regulatory molecules like Foxp3 and TGF $\beta 1$ indeed have been reported to regulate immune responses during infection thereby preventing excessive inflammation and tissue damage [36]. Another study also showed activation and expansion of both $\mathrm{T}$ effector cells and Foxp3 (+) T reg populations early in MTB infection. IL2 induces expression of both effector and regulatory $\mathrm{T}$ cells and confers resistance against severe MTB infection [37].

\section{Conclusion}

In conclusion, active TB cases versus healthy TB contacts, as well as LTBI versus uninfected healthy TB patient contacts could be accurately differentiated using expression of single genes and particularly multi-

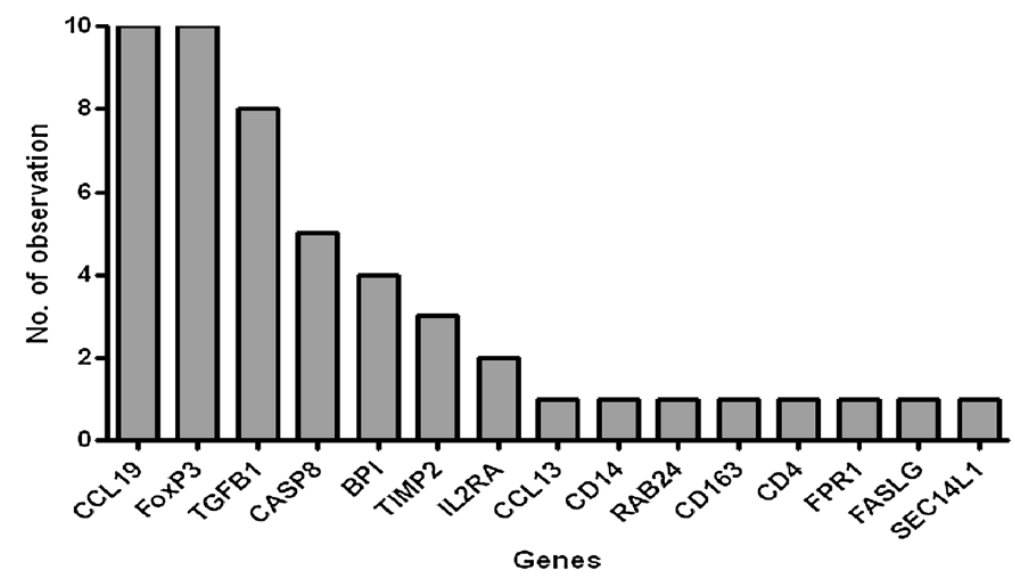

Figure 6 Frequency of individual genes in top 10 models for discriminating between LTBI and uninfected household contacts. The columns represent the number of inclusions individual markers into the most accurate five-analyte models by general discriminant for discriminating between $\mathrm{QFT}^{+}$and $\mathrm{QFT}^{-}$contacts. 
component - combinations of genes with improved discriminatory power. Hence, our findings deserve further validation in larger studies and prospective cohorts.

\section{Competing interests}

The authors declare that they have no competing interests.

\section{Authors' contributions}

AM involved in study design, laboratory work, data collection and MLPA analysis/interpretation and drafted the manuscript. AL involved in data collection, laboratory work, and MLPA analysis/interpretation and drafted the manuscript. YB involved in laboratory work and data collection. SK involved in study design and write up. MK involved in data analysis. AA involved in study design, data analysis and write up. MCK participated in study design, data analysis and write up. TO participated in study design, data analysis and write up. RH involved in study design, data analysis and write up. GW involved in study design, data analysis and write-up. All authors read and approved the final manuscript.

\section{Acknowledgements}

We gratefully acknowledge the support of the following organizations: The Bill \& Melinda Gates Foundation Grand Challenges in Global Health (grants GC6\#74 and GC12\#82); EDCTP (grant to AE-TBC, EDCTP IP. 09.32040.011); the European Commission (grants to IDEA, ADITEC, NEWTBVAC, EURYPRED, TANDEM). The funders had no role in study design, data collection and analysis, decision to publish, or preparation of the manuscript. We thank all members of our laboratories for their support.

\section{Author details}

${ }^{1}$ Armauer Hansen Research Institute, Addis Ababa, Ethiopia. ${ }^{2}$ Department of Microbiology, Immunology and Parasitology, School of Medicine, College of Health Sciences, Addis Ababa University, Addis Ababa, Ethiopia. ${ }^{3}$ Division of Molecular Biology and Human Genetics, DST/NRF Centre of Excellence for Biomedical Tuberculosis Research, MRC Centre for Molecular and Cellular Biology, Faculty of Medicine and Health Sciences, Stellenbosch University, Francie van Zijl Drive, P.O. Box 19063, 7505 Tygerberg, South Africa. ${ }^{4}$ Department of Immunology, Max Planck Institute for Infection Biology, Berlin, Germany. ${ }^{5}$ Centre for Statistical Consultation, Department of Statistics and Actuarial Sciences, University of Stellenbosch, Stellenbosch, South Africa. ${ }^{6}$ Department of Infectious Diseases, Leiden University Medical Centre, Leiden, The Netherlands.

Received: 6 January 2014 Accepted: 8 May 2014

Published: 13 May 2014

\section{References}

1. van Crevel $R$, Ottenhoff TH, van der Meer JW: Innate immunity to Mycobacterium tuberculosis. Clin Microbiol Rev 2002, 15:294-309.

2. Moller M, de Wit E, Hoal EG: Past, present and future directions in human genetic susceptibility to tuberculosis. FEMS Immunol Med Microbiol 2010, 58:3-26.

3. Ottenhoff TH, Verreck FA, Lichtenauer-Kaligis EG, Hoeve MA, Sanal O, van Dissel JT: Genetics, cytokines and human infectious disease: lessons from weakly pathogenic mycobacteria and salmonellae. Nat Genet 2002, 32:97-105.

4. Lalor MK, Floyd S, Gorak-Stolinska P, Ben-Smith A, Weir RE, Smith SG, Newport MJ, Blitz R, Mvula H, Branson K, McGrath N, Crampin AC, Fine PE, Dockrell HM: BCG vaccination induces different cytokine profiles following infant BCG vaccination in the UK and Malawi. J Infect Dis 2011, 204:1075-1085.

5. Sakai T, Matsuoka M, Aoki M, Nosaka K, Mitsuya H: Missense mutation of the interleukin-12 receptor beta1 chain-encoding gene is associated with impaired immunity against Mycobacterium avium complex infection. Blood 2001, 97:2688-2694.

6. Awomoyi AA, Marchant A, Howson JM, McAdam KP, Blackwell JM, Newport MJ: Interleukin-10, polymorphism in SLC11A1 (formerly NRAMP1), and susceptibility to tuberculosis. J Infect Dis 2002, 186:1808-1814.

7. Kim JH, Lee SY, Lee SH, Sin C, Shim JJ, In KH, Yoo SH, Kang KH: NRAMP1 genetic polymorphisms as a risk factor of tuberculous pleurisy. Int $\mathrm{J}$ Tuberc Lung Dis 2003, 7:370-375.
8. Lopez-Maderuelo D, Arnalich F, Serantes R, Gonzalez A, Codoceo R, Madero $R$, Vazquez JJ, Montiel C: Interferon-gamma and interleukin-10 gene polymorphisms in pulmonary tuberculosis. Am J Respir Crit Care Med 2003, 167:970-975.

9. Cooke GS, Campbell SJ, Sillah J, Gustafson P, Bah B, Sirugo G, Bennett S, McAdam KP, Sow O, Lienhardt C, Hill AV: Polymorphism within the interferon-gamma/receptor complex is associated with pulmonary tuberculosis. Am J Respir Crit Care Med 2006, 174:339-343.

10. Ates $O$, Musellim B, Ongen G, Topal-Sarikaya A: Interleukin-10 and tumor necrosis factor-alpha gene polymorphisms in tuberculosis. J Clin Immunol 2008, 28:232-236.

11. Mistry R, Cliff JM, Clayton CL, Beyers N, Mohamed YS, Wilson PA, Dockrell HM, Wallace DM, van Helden PD, Duncan K, Lukey PT: Gene-expression patterns in whole blood identify subjects at risk for recurrent tuberculosis. J Infect Dis 2007, 195:357-365.

12. Jacobsen M, Repsilber D, Gutschmidt A, Neher A, Feldmann K, Mollenkopf HJ, Ziegler A, Kaufmann SH: Candidate biomarkers for discrimination between infection and disease caused by Mycobacterium tuberculosis. J Mol Med (Berl) 2007, 85:613-621.

13. Lu C, Wu J, Wang H, Wang S, Diao N, Wang F, Gao Y, Chen J, Shao L, Weng $X$, Zhang Y, Zhang W: Novel biomarkers distinguishing active tuberculosis from latent infection identified by gene expression profile of peripheral blood mononuclear cells. PLoS One 2011, 6:e24290.

14. Maertzdorf J, Repsilber D, Parida SK, Stanley K, Roberts T, Black G, Walzl G, Kaufmann SH: Human gene expression profiles of susceptibility and resistance in tuberculosis. Genes Immun 2011, 12:15-22.

15. Joosten SA, Goeman JJ, Sutherland JS, Opmeer L, de Boer KG, Jacobsen M, Kaufmann SH, Finos L, Magis-Escurra C, Ota MO, Ottenhoff TH, Haks MC: Identification of biomarkers for tuberculosis disease using a novel dualcolor RT-MLPA assay. Genes Immun 2012, 13:71-82.

16. QuantiFERON-TB Gold In-Tube: technical information. http://www. cellestis.com.

17. PAXgene blood RNA procedure. http://www.preanalytix.com

18. Chegou NN, Black GF, Kidd M, van Helden PD, Walzl G: Host markers in QuantiFERON supernatants differentiate active TB from latent TB infection: preliminary report. BMC Pulm Med 2009, 9:21.

19. Kaforou M, Wright VJ, Oni T, French N, Anderson ST, Bangani N, Banwell CM, Brent AJ, Crampin AC, Dockrell HM, Eley B, Heyderman RS, Hibberd ML, Kern F, Langford PR, Ling L, Mendelson M, Ottenhoff TH, Zgambo F, Wilkinson RJ, Coin LJ, Levin M: Detection of tuberculosis in HIV-infected and -uninfected African adults using whole blood RNA expression signatures: a casecontrol study. PLoS Med 2013, 10:e1001538.

20. Sutherland JS, Loxton AG, Haks MC, Kassa D, Ambrose L, Lee JS, Ran L, van Baarle D, Maertzdorf J, Howe R, Mayanja-Kizza H, Boom WH, Thiel BA, Crampin AC, Hanekom W, Ota MO, Dockrell H, Walzl G, Kaufmann SH, Ottenhoff TH: Differential gene expression of activating Fcgamma receptor classifies active tuberculosis regardless of human immunodeficiency virus status or ethnicity. Clin Microbiol Infect 2014, 20:0230-0238.

21. Ting LM, Kim AC, Cattamanchi A, Ernst JD: Mycobacterium tuberculosis inhibits IFN-gamma transcriptional responses without inhibiting activation of STAT1. J Immunol 1999, 163:3898-3906.

22. Hwang SA, Welsh KJ, Kruzel ML, Actor JK: Lactoferrin augmentation of the $B C G$ vaccine leads to increased pulmonary integrity. Tuberc Res Treat 2011, 2011:835410.

23. Schaible UE, Collins HL, Priem F, Kaufmann SH: Correction of the iron overload defect in beta-2-microglobulin knockout mice by lactoferrin abolishes their increased susceptibility to tuberculosis. J Exp Med 2002, 196:1507-1513.

24. Abebe F, Bjune $\mathrm{G}$ : The protective role of antibody responses during Mycobacterium tuberculosis infection. Clin Exp Immunol 2009, 157:235-243.

25. Zhang M, Wang Z, Graner MW, Yang L, Liao M, Yang Q, Gou J, Zhu Y, Wu C, Liu H, Zhou B, Chen X: B cell infiltration is associated with the increased $\mathrm{IL}-17$ and IL-22 expression in the lungs of patients with tuberculosis. Cell Immunol 2011, 270:217-223.

26. Moser B, Loetscher P: Lymphocyte traffic control by chemokines. Nat Immunol 2001, 2:123-128.

27. Moller AS, Ovstebo R, Westvik AB, Joo GB, Haug KB, Kierulf P: Effects of bacterial cell wall components (PAMPs) on the expression of monocyte chemoattractant protein-1 (MCP-1), macrophage inflammatory protein1alpha (MIP-1alpha) and the chemokine receptor CCR2 by purified human blood monocytes. J Endotoxin Res 2003, 9:349-360. 
28. Saukkonen JJ, Bazydlo B, Thomas M, Strieter RM, Keane J, Kornfeld H: Betachemokines are induced by Mycobacterium tuberculosis and inhibit its growth. Infect Immun 2002, 70:1684-1693.

29. Izzo AA, Izzo LS, Kasimos J, Majka S: A matrix metalloproteinase inhibitor promotes granuloma formation during the early phase of Mycobacterium tuberculosis pulmonary infection. Tuberculosis (Edinb) 2004, 84:387-396.

30. Taylor JL, Hattle JM, Dreitz SA, Troudt JM, Izzo LS, Basaraba RJ, Orme IM, Matrisian LM, Izzo AA: Role for matrix metalloproteinase 9 in granuloma formation during pulmonary Mycobacterium tuberculosis infection. Infect Immun 2006, 74:6135-6144.

31. Ito $S$, Naito M, Kobayashi Y, Takatsuka H, Jiang S, Usuda H, Umezu H, Hasegawa G, Arakawa M, Shultz LD, Elomaa O, Tryggvason K: Roles of a macrophage receptor with collagenous structure (MARCO) in host defense and heterogeneity of splenic marginal zone macrophages. Arch Histol Cytol 1999, 62:83-95.

32. Bowdish DM, Sakamoto K, Kim MJ, Kroos M, Mukhopadhyay S, Leifer CA, Tryggvason K, Gordon S, Russell DG: MARCO, TLR2, and CD14 are required for macrophage cytokine responses to mycobacterial trehalose dimycolate and Mycobacterium tuberculosis. PLoS Pathog 2009, 5:e1000474.

33. Abebe M, Doherty TM, Wassie L, Aseffa A, Bobosha K, Demissie A, Zewdie M, Engers H, Andersen P, Kim L, Huggett J, Rook G, Yamuah LK, Zumla A: Expression of apoptosis-related genes in an Ethiopian cohort study correlates with tuberculosis clinical status. Eur J Immunol 2010, 40:291-301.

34. Abebe M, Kim L, Rook G, Aseffa A, Wassie L, Zewdie M, Zumla A, Engers H, Andersen P, Doherty TM: Modulation of cell death by M. tuberculosis as a strategy for pathogen survival. Clin Dev Immunol 2011, 2011:678570.

35. Wassie L, Demissie A, Aseffa A, Abebe M, Yamuah L, Tilahun H, Petros B, Rook G, Zumla A, Andersen P, Doherty TM: Ex vivo cytokine mRNA levels correlate with changing clinical status of ethiopian TB patients and their contacts over time. PLoS One 2008, 3:e1522.

36. Ribeiro-Rodrigues R, Resende Co T, Rojas R, Toossi Z, Dietze R, Boom WH, Maciel E, Hirsch CS: A role for CD4 + CD25+ T cells in regulation of the immune response during human tuberculosis. Clin Exp Immunol 2006, 144:25-34.

37. Chen CY, Huang D, Yao S, Halliday L, Zeng G, Wang RC, Chen ZW: IL-2 simultaneously expands Foxp3+ T regulatory and T effector cells and confers resistance to severe tuberculosis (TB): implicative Treg-T effector cooperation in immunity to TB. J Immunol 2012, 188:4278-4288.

doi:10.1186/1471-2334-14-257

Cite this article as: Mihret et al:: Combination of gene expression patterns in whole blood discriminate between tuberculosis infection states. BMC Infectious Diseases 2014 14:257.

\section{Submit your next manuscript to BioMed Central and take full advantage of:}

- Convenient online submission

- Thorough peer review

- No space constraints or color figure charges

- Immediate publication on acceptance

- Inclusion in PubMed, CAS, Scopus and Google Scholar

- Research which is freely available for redistribution

Submit your manuscript at www.biomedcentral.com/submit

C Biomed Central 